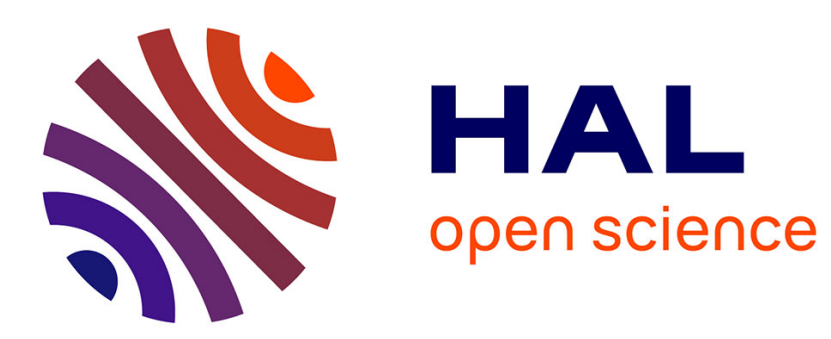

\title{
Ferrite-Capsulated Porous Silica Microspheres for Ultrasonic Contrast Agents
}

\author{
M. Zhang, Y. Kitamoto, M. Abe
}

\section{To cite this version:}

M. Zhang, Y. Kitamoto, M. Abe. Ferrite-Capsulated Porous Silica Microspheres for Ultrasonic Contrast Agents. Journal de Physique IV Proceedings, 1997, 07 (C1), pp.C1-669-C1-670. 10.1051/jp4:19971273 . jpa-00254985

\section{HAL Id: jpa-00254985 https://hal.science/jpa-00254985}

Submitted on 1 Jan 1997

HAL is a multi-disciplinary open access archive for the deposit and dissemination of scientific research documents, whether they are published or not. The documents may come from teaching and research institutions in France or abroad, or from public or private research centers.
L'archive ouverte pluridisciplinaire HAL, est destinée au dépôt et à la diffusion de documents scientifiques de niveau recherche, publiés ou non, émanant des établissements d'enseignement et de recherche français ou étrangers, des laboratoires publics ou privés. 


\title{
Ferrite-Capsulated Porous Silica Microspheres for Ultrasonic Contrast Agents
}

\author{
M. Zhang, Y. Kitamoto and M. Abe
}

Department of Physical Electronics, Tokyo Institute of Technology, O-okayama, Meguro-ku, Tokyo 152, Japan

\begin{abstract}
Porous silica microspheres, $\sim 2.2 \mu \mathrm{m}$ in average diameter, were encapsulated with magnetite $\left(\mathrm{Fe}_{3} \mathrm{O}_{4}\right)$ by ferrite plating in an aqueous solution of $\mathrm{FeCl}_{2}$ at $65^{\circ} \mathrm{C}$. Using the resultant ferrite-capsulated particles as ultrasonographic contrast agents (in which air trapped in the pores scatters ultrasonic waves), we tried to visualize still and flowing waters in holes and a channel perforated in agar blocks by using a 7.5MHz B-mode echograph. Clear image enhancement was successfully obtained only when the ferrite-capsulated particles were evaporated in air before they were dispersed in the waters. This is because, during ferrite plating in the aqueous solution, the pores were permeated with water, which was expelled by the evaporation and, then, substituted by air when the particles were exposed to air again.
\end{abstract}

\section{INTRODUCTION}

Ultrasonographic Contrast agents which are controllable by external magnetic field were fabricated by Moriya and Seki[1], who coated the surface of hollow glass microspheres, $51 \mu \mathrm{m}$ in average diameter, with magnetite; the air in the hollows scatters ultrasound waves. This type of contrast agent can not be made smaller than $\sim 10 \mu \mathrm{m}$ in diameter, because hollow glass spheres available at present are limited in size to $\sim 10 \mu \mathrm{m}$ at smallest. Size less than several microns are desirable for the contrast agent particles in order to have minimum effect on the test liquid flow.

In this paper we describe that magnetically controllable ultrasonic contrast agents can be fabricated by coating the surface of porous silica (PS) microspheres with magnetite by ferrite plating; air trapped in the pores scatters ultrasound waves, enhancing echogenicity. The novel contrast agents have the following advantages: (1) they can be submicron in size, (2) their virtual specific gravity is adjustable to that of ambient fluid by properly choosing the thickness of the magnetite whose density $(\sim 5.2)$ is much larger than that $(\sim 0.2)$ of PS, and (3) they are stable, advantageous for engineering sonography. Furthermore, the novel magnetic contrast agents of submicron size are potentially applied to clinical sonography, because small sized magnetic capsulated particles which are injected into organs through vascular can be recovered by magnetic force, permeating capillary vessels[2].

\section{EXPERIMENTS}

The PS microspheres, $2.2 \mu \mathrm{m}$ in average diameter, were coated with magnetite $\left(\mathrm{Fe}_{3} \mathrm{O}_{4}\right)$ by ferrite-plating using an aqueous solution of $\mathrm{FeCl}_{2}[3]$.

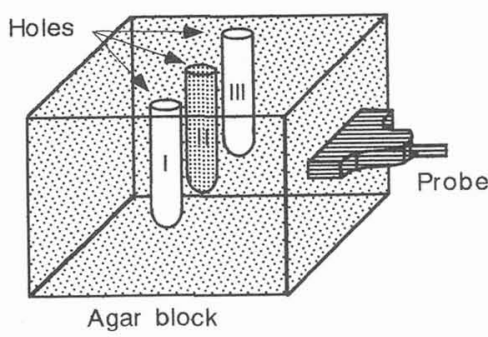

(a)

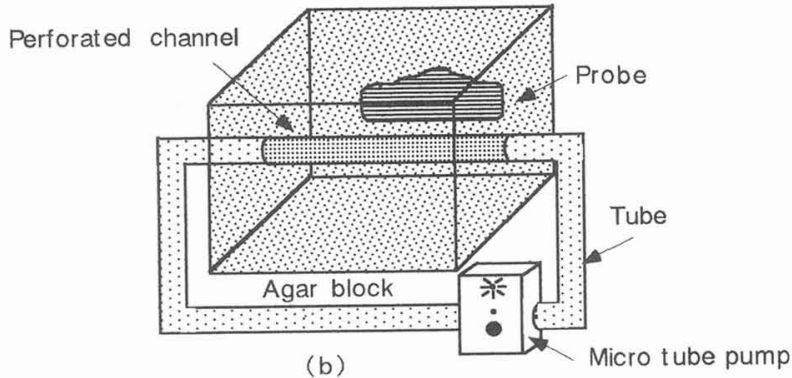

(b)

Figure 1: Agar blocks for B-mode imaging for still waters in holes (a), and flowing water through a channel (b). 


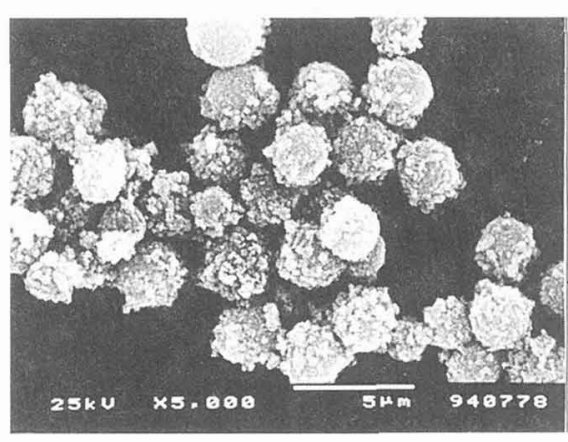

Figure 2: Scanning electron micrographs for ferritecapsulated PS microspheres

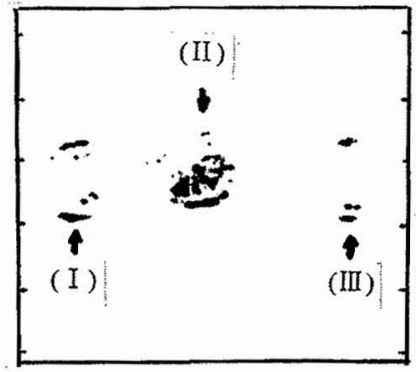

(a)

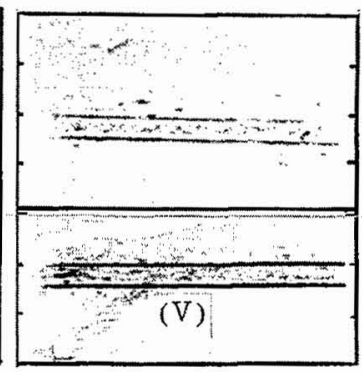

(b)
Figure 3: (a) shows sonograms for still waters containing bare PS particles (I), evaporated, ferrite-coated particles (II), and no particles (III). (b) shows sonograms for flowing water containing evaporated, ferrite-coated particles (IV) and commercial contrast agents (V).

The ferrite-coated particles were evaporated in vacuum at room temperature for 6 hours to expel water which permeated the pores of the PS particles during plating. The particles were then dispersed in a distilled water using a $40 \mathrm{kHz}$ ultrasonic washing machine. After discarding the precipitated particles, the supernatant water was injected into holes and a flow loop system shown in Fig. 1, in order to sonically image the still and flowing waters, respectively, using a 7.5MHz B-mode medical ultrasonograph. The holes were made, $10 \mathrm{~mm}$ in diameter and $65 \mathrm{~mm}$ in length, in an agar block (a) of $13 \times 11 \times 8 \mathrm{~cm}^{3}$ size, to which the probe of the sonograph was contacted. Through a similar agar block (b), a channel (2 $\mathrm{mm}$ in diameter, $130 \mathrm{~mm}$ in length) was perforated, which was connected to a micro tube pump with vinyl tubes ( $3 \mathrm{~mm}$ in inner diameter), constituting the flow loop system. For comparison, we also took sonograms of still or flowing water which contained no particles, bare (non-ferrite-coated) PS particles, as-coated (non-evacuated) particles, or commercial contrast agents of low density polyethylene spheres (Flo-beads LE-1080, Sumitomo Seika Chemicals Co. Ltd.) with average size of $6 \mu \mathrm{m}$.

\section{RESULTS}

As Fig. 2 shows, the surfaces of PS microspheres were covered entirely with the ferrite, which was polycrystalline magnetite with single phase spinel structure as examined by X-ray diffractometry, though contained a slight portion of paramagnetic impurity phase as examined by Mössbauer spectroscopy[3]. The magnetite ferrite coat was estimated to be $0.06 \sim 0.08 \mu \mathrm{m}$ in thickness with which the virtual specific gravity of the ferrite coated particles was nominally calculated as $1.0 \sim 1.2$, assuming the gravity of the magnetite coat as $\mathbf{5 . 2}$ (reported for bulk sample) and that of the porous silica as $\mathbf{0 . 2}$ (written in the catalogue).

Figure 3(a) shows the ultrasonic echographic images obtained for the still waters containing the bare PS particles, evaporated ferrite-coated particles, and no particles. The evaporated ferrite-coated particles gave a much stronger echogenicity than the bare PS particles. The as-coated particles also gave similar images which, however, faded away only in 30 seconds. On the contrary, the echogenicity of the evaporated ferrite-coated particles was kept stable for longer than 3 hours. After being dried and kept in air for one month, the particles exhibited similar echogenicity when dispersed in water again.

These results can be understood as follows: when the ferrite-coated PS particles were dispersed in water for plating or sonographic imaging, the water permeated the pores of the PS particles, expelling the air in the pores. Accordingly, the bare particles exhibited no echogenicity. On the other hand, the as-coated particles exhibited echogenicity by air bubbles adsorbed on the surface of the ferrite coat, which were desorbed after 30 seconds, thus fading away the sonogram. When the coated particles were evaporated, the water trapped in the pores were expelled, penetrating through the ferrite coat which is not completely dense with a columnar structure[4]. When the vacuum was destroyed to expose the particles to air again, the pores were filled with air, which can not be substituted by water any more even when they were dispersed in water for the imaging, because the air was confined in a closed space which was surrounded by the ferrite coat. Therefore, the air, and its echogenicity of the evaporated coated particles, was kept stable for long period.

Figure 3(b) shows the echographic images for the flowing waters which contained the evaporated, ferrite-coated particles (IV) and the commercial low density polyethylene spheres (V). By the ferrite-coated PS particles sonographic imaging for the flowing water was obtained as clear as that by the commercial contrast agents.

\section{CONCLUDING REMARKS}

The evaporated, ferrite coated particles facilitated echographic imaging of the flowing water as clear as obtained by the commercial contrast agents of low density polyethylene spheres on the market.

\section{References}

[1] T. Moriya and M. Seki, Proceedings of the Sixth International Conference on Ferrites (ICF6), pp. 295-298, 1992.

[2] Private communication from Masami Tanaka, Nippon Paint Co., Ltd.

[3] M. Zhang, Q. Zhang, T. Itoh and M. Abe, IEEE Transactions on Magnetics, No. 6, 30(1994)4692-4694.

[4] M. Abe, Y. Tamaura, Y. Goto, N. Kitamura and M. Gomi, J. Appl. Phys. No. 8, 61(1987)3211-3213. 